\title{
Correspondence
}

\section{Cost-effective prescribing}

Singh et al's ${ }^{1}$ discussion of cost-effective prescribing is timely. Small changes in prescription writing habits can produce significant savings without noticeable change in clinical practice. A clear example is that of venlafaxine modified release which is produced in both capsule and tablet form. These are bioequivalent but vary widely in cost. It has been calculated that switching from capsule to tablet would save our local healthcare economy about $£ 148000$ a year. The only change required of doctors would be to specify tablets on the prescription, thus ensuring the more cost-effective preparation is dispensed. The twice-daily formulation is cheaper still but would require a greater degree of change and perhaps affect adherence. Fluoxetine provides another example: fluoxetine $10 \mathrm{mg}$, a dose often used in child and adolescent mental health services, is not available in tablet form in the UK. Importing a supply can result in a single prescription cost of several hundred pounds, but specifying fluoxetine syrup ensures the cost remains less than $\notin 10$. $^{2}$

Clearly, significant savings are to be had without compromising patient care or clinical autonomy. With regular support from a vigilant chief pharmacist and medicines management committee, the vagaries of the drug tariff could be navigated and the drug budget spent more cost-effectively.

1 Singh DK, Khawaja S, Pala I, Khaja J, Krishnanu R, Walker H, et al. Awareness of the cost of psychotropic medication among doctors: a service evaluation. Psychiatrist 2010; 34: 364-6.

2 British Medical Association, Royal Pharmaceutical Society of Great Britain. British National Formulary (issue 59). BMJ Group, Pharmaceutical Press, March 2010.

Sara Smith is Consultant Psychiatrist, Dudley and Walsall Mental Health Partnership Trust, email: sara.smith@dwmh.nhs.uk

doi: $10.1192 / \mathrm{pb} .34 .12 .537$

\section{Making a noise}

Tom Burns ${ }^{1}$ rightly draws our attention to the quiet revolution that removed continuity of care from consultant psychiatrists with the 'functional split' between in-patient and community services. Despite my initial vocal resistance to the model, now that it is established in my place of work, I would not want to go back to being the prime focus for hundreds of patients throughout their mental healthcare journey. Since the functional model was introduced, I have felt more able to do a good job. Service users may be less worried about this change than many service providers. ${ }^{2}$

Continuity of care through one person can reduce patient choice and lead to overdependent relationships. Second opinions are much easier to get when patients transfer between hospital and community. Care coordinators are slowly taking on continuity of care, although they sometimes struggle with the authority of consultants and managers. We can help ameliorate that by working in a cooperative and consultative style.

Some psychiatrists fear that the removal of consultantcentred continuity could help make psychiatrists redundant. Surely we need to value our expertise more than our personal carrying capacity. In future, we need to demonstrate our expert role by the good outcomes we achieve in collaboration with our teams, not simply by having lots of patients on our caseloads. We are better employed as consultants than care coordinators.

Locally, the functional model has enabled me to develop myself, my team and my service. The patient suicide rate has not increased. The more serious National Patient Safety Agency incidents (levels 3, 4 and 5) are less frequent. Patient and staff satisfaction is getting better. We could do more to address communication across the interfaces, but overall, my personal experience of the functional model has been positive.

I would prefer to improve the functional model, rather than re-combine hospital and community work. It would be satisfying to get it working well, before the next upheaval. In-patient consultants should give themselves leave in the community and community consultants should visit their colleagues in hospital. We should disentangle history taking and examination from engagement, so patients do not have to repeat their stories as they move between services - we could review our colleagues' notes with the patient rather than start afresh. It is a different way of working that allows us to be involved in the care of many service users, but as part of a team.

A US politician, Pauline R. Kezer said, 'Continuity gives us roots; change gives us branches, letting us stretch and grow and reach new heights.' There is value in continuity and value in change. The Royal College of Psychiatrists Occasional Paper, Looking Ahead, calls for a systematic review of models of mental healthcare using standardised outcomes. ${ }^{3}$ However, at no point does the paper recommend that consultant psychiatrists again take on the central role of personally providing continuity of care for all patients. Instead, Looking Ahead explicitly values the expertise of consultant psychiatrists, our availability for rapid review and the advice we give to others (recommendation 3 ). That is something worth making a noise about.

1 Burns T. The dog that failed to bark. Psychiatrist 2010; 34: 361-3.

2 Singhal A, Garg D, Rana AK, Naheed M. Two consultants for one patient: service users' and service providers' views on 'New Ways'. Psychiatrist 2010; 34: 181-6.

3 Royal College of Psychiatrists. Looking Ahead: Future Development of UK Mental Health Services (Occasional Paper OP75). Royal College of Psychiatrists, 2010.

David Yeomans is Community Consultant Psychiatrist with Leeds Partnerships NHS Foundation Trust, email: d.yeomans@virgin.net doi: $10.1192 /$ pb.34.12.537a

\section{Pessimism}

Professor Burns ${ }^{1}$ is right to draw attention to possible damaging effects of separating consultant responsibility for in-patient and out-patient care. My past experience of both overall and out-patient-only responsibility supports the points he makes. Particularly striking was distress for patients at having to get to know a new consultant and go back over longterm histories at the particularly fraught time of admission, as 